\title{
Diagnostic imaging of pathologic changes in the ankle joint of ballet dancers (literature review)
}

\author{
V.A. Nechaev' ${ }^{1}$ A.Iu. Vasil'ev ${ }^{2,3}$ \\ ${ }^{1}$ City Clinical Hospital No 4 of Moscow Health Department, Moscow, Russian Federation \\ ${ }^{2}$ A.I. Yevdokimov Moscow State University of Medicine and Dentistry, Moscow, Russian Federation \\ ${ }^{3}$ Central Research Institute of Radiation Diagnostics Ltd., Moscow, Russian Federation
}

\begin{abstract}
The ankle plays an essential role in establishing lower extremity stability that is important for such physically demanding sports as ballet. Non-physiological movements in the joint that force the ankle into extreme positions and repetitive stress during intense practice and performances predispose to the development of pathological conditions. Radiological studies are an integral part of diagnostic algorithm for the search of the causes of pain. The aim was to conduct a literature review on diagnostic imaging of ankle pathology in ballet dancers. Methods Literature searching was performed via databases of PubMed, Cochrane library, eLibrary.ru, etc. using the following terms: ankle pathology in ballet dancers, bballet ankle imaging, ballet ankle. Conclusions Standard radiographs are usually the initial screening modality to evaluate patients, including ballet dancers with lower extremity symptoms, nonetheless, MRI provides a superb global evaluation of each joint, including deep structures and detecting possible causes of pain.

Keywords: radiography, computed tomography, magnetic resonance imaging, diagnostic ultrasonography, ballet dancer, ankle pathology
\end{abstract}

The classical positions in which ballet dancers stand, force the foot and ankle into extreme positions that is known as demi-plié (maximum dorsiflexion) and en pointe (maximum plantarflexion). The normal range of motion in an adult population ranges between $20^{\circ}$ dorsiflexion and $50^{\circ}$ plantarflexion. The mean ankle-foot plantarflexion can be $113^{\circ}$ in professional ballet dancers. Non-physiological movements in the joint that force the ankle into extreme positions and repetitive stress during intense practice and performances predispose to the development of pathological conditions [1-3].

Foot and ankle pain is common in ballet dancers and account for more than $57 \%$ of all dance injuries. Although clinical examination often points to the underlying cause, imaging is often necessary to confirm the diagnosis and thus ensure appropriate future management. Imaging findings of ankle injuries are not ballet-specific. Foot and ankle injuries include those that are specific to ballet dancers because of the unique physical maneuvers required to effectively perform and will be discussed in details $[4,5]$. The physical demands of dance class, long rehearsals and performances can predispose the dancer to injury. In addition, the tendons and ligaments are subject to repetitive stress during intense practise of ballet techniques, including en pointe and demi-pointe.
Most musculoskeletal injuries are caused by overuse rather than acute injuries $[5,6]$.

Numerous studies report high rates of ligamentous injury as the most common traumatic injuries encountered in ballet. Disruption of the lateral ligament complex is caused by inversion injuries and accounts for the vast majority of ligament injuries. The lateral ligament complex is composed of the anterior talofibular ligament, the calcaneofibular ligament and the posterior talofibular ligament. MRI is highly sensitive at detecting ligamentous injuries. The anterior talofibular ligament ligament is best demonstrated on axial T2 weighted images. Partial tears are visible as areas of high signal intensity with thickening on $\mathrm{T} 2$ weighted images. Complete tears are seen as discontinuity of the ligament with high signal intensity between the torn segments. Ultrasonographic examination of the ankle can identify a ligamentous tear seen as a hypoechoic gap or disturbed ligament integrity with fluid between the torn fragments. Ultrasoound is a readily available modality that is of great value in assessing pathologies of foot and ankle [7-9].

Tendon abnormalities of the distal lower extremity and foot are frequently found as the cause of ankle pain and foot malfunction in ballet dancers. One of the most frequent complaints is tendinopathy of the 
flexor hallucis longus (FHL).The FHL tendon passes within a fibro-osseous tunnel between the medial and lateral tubercles of the posterior talus, and en pointe and demi-pointe positions put substantial stress on the FHL that is either compressed or overstretched while performing the positions. Thickening of the tendon and patchy high signal on T2 weighted or short tau inversion recovery (STIR) images within the tendon are features of tendonitis. Fluid around the tendon often indicates tenosynovitis $[7,10]$.

Chronic ankle pain in ballet dancers can be caused by tibiotalar impingement syndrome that limits full range of movement. Symptoms are due to compression of soft tissues or osseous structures during particular movements [11-13]. The most commonly described are posterior and anterior impingement. Anterior ankle impingement is either secondary to hypertrophied soft tissue interposed in the anterior ankle joint or proliferation of osteophytes (bony and soft-tissue impingement) that limit the open space between the anterior lip of the tibia and the dorsal talar neck. The presence of osteophytes does not always correlate with impingement suggesting that soft tissue changes must also be necessary [11].

D. Nihal et al. (2005) retrospectively reviewed 11 elite dancers (12 ankles) clinically diagnosed with anterior ankle impingement and tibiotalar exostoses radiographically noted in $50 \%$ of the ankles. The absence of osteophytes did not rule out soft-tissue impingement [14]. An oblique anteromedial radiograph was proposed by J.L. Tol et al. to locate anteromedial osteophytes. The authors demonstrated a dramatic increase in the sensitivity of radiographs in detecting anterior tibial and talar osteophytes. It was important during preoperative evaluation to determine the anatomic location of osteophytes because the anteromedial aspect of the ankle joint was more difficult to visualize arthroscopically [15]. A prospective study performed by J. Haller et al. (2006) who evaluated MRI in the setting of chronic ankle pain showed modest sensitivity of MRI for anterior tibial osteophytes (67\%), although it had high sensitivity (89\%) for soft-tissue impingement featuring synovitis, capsular thickening and the anterior talofibular ligament, scar and granulation tissue, osteochodral lesion of the talus trochlea $[7,16]$.

Posterior impingement syndrome is common in ballet dancers due to the forced repetitive plantar flexion associated with the en pointe position.
Symptoms are due to compression of soft-tissue structures between the calcaneus and the posterior plafond of the tibia. The presence of an os trigonum (an accessory bone) or a Steida process (an enlarged posterolateral talar process), hypertrophied posterior tibiofibular ligament can contribute to the problem. The presence of the above symptoms does not automatically indicate impingement syndrome. V. Zwiers et al. (2018) found a prevalence of $30.3 \%$ of os trigonum in patients with no signs of posterior impingement syndrome [17]. W. Albisetti et al. (2009) examined 186 young trainee ballet dancers. Twelve suffered from posterior ankle pain, and six of those (50\%) had radiologically detected os trigonum [18].

The posterior impingement (PIM) view has been recommended by J.I. Wiegerinck et al. (2014) instead of a conventional lateral view for symptomatic hindfoot pain. The PIM view is a lateral, 25-degree external rotation, oblique view of the ankle, which has shown significant superior diagnostic accuracy compared with the lateral view in the detection of os trigonum and differentiation from hypertrophic posterior talar process [19]. Computed tomography is an important imaging modality when investigating skeletal anatomy, viewing osteophytes, fractures, osteochondral lesions, free bone fragments causing impingement syndrome with the symptoms being not evident on plain radiographs [7]

MRI is a useful diagnostic tool in posterior ankle impingement syndrome (PIAS). A retrospective review done by K.A. Peace et al. (2004) was undertaken of 25 MRI examinations of the ankle performed on ballet dancers presented with symptoms and signs suggestive of PAIS. Anatomical variants predisposing to PAIS included tuberosity arising from the superior calcaneum (64\%), the posterior tibiofibular ligament (48\%), os trigonum (28\%), a Steida process (16\%). Signs of synovitis were observed in all cases. Tenosynovitis of flexor hallucis longus (68\%) and thickening of the posterior capsule (68\%) were also common. Additional sequence produced with plantar flexion in 11 (44\%) cases showed soft tissues compressed between bone components. Thus, MRI clearly demonstrated the anatomical variants and range of osseous and softtissue abnormalities associated with PAIS [10].

Ballet dancers whose occupation involves specific, repetitive lower extremity biomechanical 
stresses were shown to have a relatively high incidence of stress fractures of the foot and ankle. I. Elias et al. (2008) reviewed MR imaging performed on 12 ankles of 11 active high performance professional ballet dancers who experienced ankle pain. Bone marrow edema was seen only in the talus, and was a common finding observed in $75 \%$ of the cases. On fluid-sensitive sequences, bone marrow edema was ill-defined and centered in the talar neck or body, although in three cases it extended to the talar dome. Bone marrow edema was thought to be a specific MRI finding in the talus of professional ballet dancers, likely related to biomechanical stress reactions, due to their frequently performed unique maneuvers [20].
Ballet dancers may suffer stress-related injuries due to atypical high-load forces and repetitive stress. The talus, calcaneus and Stieda process are commonly affected. Regions of marrow edema with clear hypointense fracture line can be visible on T1-weighted MR images $[4,21]$. The distal tibial physis can be the site of chronic overuse injuries in young athletes. D.L. Bernholt et al. (2013) reported a 9-year-old recreational gymnast and dancer whose convenytional radiographs showed widening of the distal tibial physis medially, and just proximal to the physis, cystic changes in the metaphysis along with a band of sclerosis. The patient was diagnosed with overuse stress injury affecting the physis secondary to athletic activity. A 30-month follow-up showed regression of pathological changes [21].

\section{CONCLUSION}

The ankle of a ballet dancer is particularly vulnerable to injury. The variety of statically challenging and non-physiological positions of the ballet dancer's lower extremities forces the foot and ankle into extreme positions that is known as demi-plié (maximum dorsiflexion) and en pointe (maximum plantarflexion). Ankle pain is very common in ballet dancers. The most common injuries are ligament abnormalities, impingement syndromes, tendon abnormalities and stress injuries. Conventional radiography remains a major modality in the evaluation of bony structures, detection of osteophytes, Stieda process or os trigonum. MRI can directly visualize the articular structures and is useful in determining the cause of pain in most cases.

\section{REFERENCES}

1. Russel J.A., Yoshioka H. Assessment of female ballet dancers' ankles in the en pointe position using high field strength magnetic resonance imaging. Acta Radiol., 2016, vol. 57, no. 8, pp. 978-984. DOI: 10.1177/0284185115616295.

2. Russell J.A., Shave R.M., Kruse D.W., Koutedakis Y., Wyon M.A. Ankle and foot contributions to extreme plantar- and dorsiflexion in female ballet dancers. Foot Ankle Int., 2011, vol. 32, no. 2, pp. 183-188. DOI: 10.3113/FAI.2011.0183.

3. Russell J.A., Shave R.M., Yoshioka H., Kruse D.W., Koutedakis Y., Wyon M.A. Magnetic resonance imaging of the ankle in female ballet dancers en pointe. Acta Radiol., 2010, vol. 51, no. 6, pp. 655-661. DOI: 10.3109/02841851.2010.482565.

4. Haller J., Bernt R., Seeger T., Weissenbäck A., Tüchler H., Resnick D. MR-imaging of anterior tibiotalar impingement syndrome: agreement, sensitivity and specificity of MR-imaging and indirect MR-arthrography. Eur. J. Radiol., 2006, vol. 58, no. 3, pp. 450460. DOI: 10.1016/j.ejrad.2006.03.008.

5. Smith P.J., Gerrie B.J., Varner K.E., McCulloch P.C., Lintner D.M., Harris J.D. Incidence and prevalence of musculoskeletal injury in ballet. Orthop. J. Sports Med., 2015, vol. 3, no. 7, pp. 2325967115592621. DOI: 10.1177/2325967115592621.

6. Luk P., Thordarson D., Charlton T. Evaluation and management of posterior ankle pain in dancers. J. Dance Med. Sci., 2013, vol. 17, no. 2, pp. 79-83. DOI: 10.12678/1089-313x.17.2.79.

7. Hayashi D., Roemer F.W., D’Hooghe P., Guermazi A. Posterior ankle impingement in athletes: Pathogenesis, imaging features and differential diagnoses. Eur. J. Radiol., 2015, vol. 84, no. 11, pp. 2231-2241. DOI: 10.1016/j.ejrad.2015.07.017.

8. Nault M.L., Kocher M.S., Micheli L.J. Os trigonum syndrome. J. Am. Acad. Orthop. Surg., 2014, vol. 22, no. 9, pp. 545-553. DOI: $10.5435 / J A A O S-22-09-545$.

9. Rehmani R., Endo Y., Bauman P., Hamilton W., Potter H., Adler R. Lower extremity injury patterns in elite ballet dancers: ultrasound/ MRI imaging features and an institutional overview of therapeutic ultrasound guided percutaneous interventions. HSS J., 2015, vol. 11, no. 3, pp. 258-277. DOI: 10.1007/s11420-015-9442-z.

10.Peace K.A., Hillier J.C., Hulme A., Healy J.C. MRI features of posterior ankle impingement syndrome in ballet dancers: a review of 25 cases. Clin. Radiol., 2004, vol. 59, no. 11, pp. 1025-1033. DOI: 10.1016/j.crad.2004.02.010.

11.Lavery K.P., McHale K.J., Rossy W.H., Theodore G. Ankle impingement. J. Orthop. Surg. Res., 2016, vol. 11, no. 1, pp. 97. DOI: 10.1186/s13018-016-0430-x.

12.Roche A.J., Calder J.D., Lloyd Williams R. Posterior ankle impingement in dancers and athletes. Foot Ankle Clin., 2013, vol. 18, no. 2, pp. 301-318. DOI: 10.1016/j.fcl.2013.02.008. 
13.Kuznetsov I.A., Velichko K.E., Shchepkina E.A. Osobennosti lecheniia zadnego impidzhment-sindroma golenostopnogo sustava $\mathrm{u}$ artistov baleta i sportsmenov [Special features of treatment of the posterior impingement-syndrome of the ankle in ballet dancers and sportsmen]. Travmatologiia i Ortopediia Rossii, 2015, no. 3 (77), pp. 61-69. (in Russian) Available at: https://cyberleninka. $\mathrm{ru} /$ article/v/osobennosti-lecheniya-zadnego-impidzhment-sindroma-golenostopnogo-sustava-u-artistov-baleta-i-sportsmenov (accessed 03.03.2017).

14.Nihal A., Rose D.J., Trepman E. Arthroscopic treatment of anterior ankle impingement syndrome in dancers. Foot Ankle Int., 2005, vol. 26, no. 11, pp. 908-912. DOI: 10.1177/107110070502601102.

15.Tol J.L., van Dijk C.N. Anterior ankle impingement. Foot Ankle Clin., 2006, vol. 11, no. 2, pp. 297-310. DOI: 10.1016/j. fcl.2006.02.002.

16.O’Kane J.W., Kadel N. Anterior impingement syndrome in dancers. Curr. Rev. Musculoskelet. Med., 2008, vol. 1, no. 1, pp. $12-16$. DOI: $10.1007 / \mathrm{s} 12178-007-9001-4$.

17.Zwiers R., Baltes T.P.A., Opdam K.T.M., Wiegerinck J.I., van Dijk C.N. Prevalence of os trigonum on CT imaging. Foot Ankle Int., 2018, vol. 39, no. 3, pp. 338-342. DOI 10.1177/1071100717740937.

18.Albisetti W., Ometti M., Pascale V., De Bartolomeo O. Clinical evaluation and treatment of posterior impingement in dancers. Am. J. Phys. Med. Rehabil., 2009, vol. 88, no. 5, pp. 349-354. DOI: 10.1097/PHM.0b013e31817fa31d.

19.Wiegerinck J.I., Vroemen J.C., Van Dongen T.H., Sierevelt I.N., Maas M., Van Dijk C.N. The posterior impingement view: an alternative conventional projection to detect bony posterior ankle impingement. Arthroscopy, 2014, vol. 30, no. 10, pp. $1311-1316$. DOI: 10.1016/j.arthro.2014.05.006.

20.Elias I., Zoga A.C., Raikin S.M., Peterson J.R., Besser M.P., Morrison W.B., Schweitzer M.E. Bone stress injury of the ankle in professional ballet dancers seen on MRI. BMC Musculoskelet. Disord., 2008, vol. 9, pp. 39. DOI: 10.1186/1471-2474-9-39.

21.Bernholt D.L., Garzon-Muvdi J., Chhabra A., McFarland E.G. Stress fracture of the distal tibial physis in an adolescent recreational dancer. Am. J. Sports Med., 2013, vol. 41, no. 7, pp. 1649-1652. DOI: 10.1177/0363546513485938.

Received: 08.08.2018

\section{Information about the authors:}

1. Valentin A. Nechaev, M.D., Ph.D., City Clinical Hospital No 4 of Moscow Health Department, Moscow, Russian Federation, Email:dfkz2005@gmail.com

2. Aleksandr Iu. Vasil'ev, M.D., Ph.D., Professor, Corresponding Member of RAS,

A.I. Yevdokimov Moscow State University of Medicine and Dentistry, Moscow, Russian Federation, Central Research Institute of Radiation Diagnostics Ltd., Moscow, Russian Federation, Email: auv62@mail.ru 